\title{
Correction to: Stability analysis of fractional-order Colpitts oscillators
}

\author{
Lobna A. Said' ${ }^{1}$ Omar Elwy' ${ }^{1}$ Ahmed H. Madian ${ }^{1,2}$ (1) $\cdot$ Ahmed G. Radwan ${ }^{3,4} \cdot$ Ahmed M. Soliman $^{5}$
}

Published online: 7 September 2019

(C) Springer Science+Business Media, LLC, part of Springer Nature 2019

\section{Correction to: Analog Integrated Circuits and Signal Processing https://doi.org/10. 1007/s10470-019-01501-2}

Unfortunately, in the original version of the article some typos occurred. The typos have been corrected with this erratum. Below are the corrections:

(1) Table 1 contains 2 repeated figures. There should be just the first two horizontal figures and then the equation cell.

(2) In Eq. 6, the first matrix row contains the term: $a-\left(r_{e}+\frac{1}{g_{m}}+\frac{r_{e}}{g_{m} r_{0}}\right)$, which is wrong. The right term is without a, and should be $-\left(r_{e}+\frac{1}{g_{m}}+\frac{r_{e}}{g_{m} r_{0}}\right)$.

The original article can be found online at https:// doi.org/10.1007/s10470-019-01501-2.

Ahmed H. Madian

amadian@nu.edu.eg

1 Nanoelectronics Integrated Systems Center (NISC), Nile University, Giza, Egypt

2 Radiation Engineering Department, NCRRT, Egyptian Atomic Energy Authority, Giza, Egypt

3 Engineering Mathematics and Physics Department, Faculty of Engineering, Cairo University, Giza, Egypt

4 School of Engineering and Applied Sciences, Nile University, Giza, Egypt

5 Electronics and Communication Engineering Department, Cairo University, Giza, Egypt
(3) In Table 4, the first term in the first equation should be $C_{1} C_{2} L \omega^{(\alpha+\beta)} \sin \left(\frac{(\beta+2 \alpha) \pi}{2}\right)$ by making $(\alpha+\beta)$ the power of $\omega$.

(4) In Sect. 7, the simulated frequency is $86.25 \mathrm{kHz}$ not $86.25 \mathrm{~Hz}$.

Publisher's Note Springer Nature remains neutral with regard to jurisdictional claims in published maps and institutional affiliations. 